\title{
LILITH EN EL ARTE DECIMONÓNICO. ESTUDIO DEL MITO DE LA FEMME FATALE
}

\author{
Golrokh EETESSAM PÁRRAGA \\ Universidad Complutense de Madrid \\ golyep@gmail.com
}

Resumen: La figura de Lilith como abstracción de la mujer fatal vivió un importante resurgimiento durante el siglo XIX. La literatura y las artes plásticas se poblaron de este imaginario que ha llegado hasta nuestros días convertido en tópico.

Abstract: The figure of Lilith as the abstraction of the femme fatale, lived an important resurgence during the 19th century. Literature and Plastics arts were populated with this imaginary world that has arrived to our days converted in a topic.

Palabras clave: Arte. Siglo XIX. Lilith. Mito.

Key Words: Art. Century XIX. Lilith. Myth 
La segmentación de los estudios literarios en los últimos años ha ayudado a que proliferen trabajos sobre temas que, hasta ahora, se habían tratado tangencialmente y desde un punto de vista muy parcial y poco profundo. La imagen de la mujer, de la femme fatale, encarnada en la figura de Lilith dentro del imaginario literario y pictórico de la cultura occidental, es uno de los temas que más interés ha despertado entre los investigadores.

Es imposible tratar esto sin pasar, de puntillas y con cuidado, junto a la visión más reivindicativa y feminista de la historia. Sin embargo, éste no pretende ser un trabajo orientado hacia la defensa o el ataque de las condiciones sufridas por la imagen de la mujer en la literatura y la pintura de signo marcadamente masculino, y, en alguna ocasión, evidentemente misógino. Es la investigación objetiva (dentro de lo que puede tener de objetivo el análisis de la subjetividad artística) de una serie de mitemas presentes en el imaginario colectivo desde la antigüedad.

Desde que Pandora abrió la caja, Lilith se negó a yacer bajo Adán y Eva desafió a Dios probando el fruto del Árbol de la Ciencia, la imagen de la mujer pecadora y culpable de abocar al desastre a toda la humanidad ha sido un tema recurrente en el arte. Analizar minuciosamente esta presencia sin acotarla en un tiempo es una tarea más propia para un libro voluminoso que para la naturaleza de este trabajo. Es por esto que me ha parecido más adecuado restringir la investigación al arte del periodo decimonónico.

En esta época, el cambio social comenzaba a tomar cuerpo en el día a día de las ciudades. El pueblo se organizaba, la revolución industrial afianzaba sus cambios y la mujer daba los primeros y trémulos pasos hacia el camino de su emancipación. Es en este momento, entre la represión de la moral victoriana y el decadentismo fin de siècle, cuando la imagen de la mujer como instigadora del pecado renace con fuerza y ocupa la mayor parte de la imaginería de los hombres del arte.

\section{APROXIMACIONES A LA FIGURA DE LILITH}

\subsection{Orígenes de la tradición}

Su nombre original en acadio es Lilitu, que proviene de la palabra "lil", que en este idioma significa "viento" o "espíritu". Su traducción dio probablemente origen a una confusión, pues "lil" en hebreo significa noche. Otras versiones, sin embargo, apuntan hacia un posible nacimiento en la cultura su- 
meria de Mesopotamia, con un origen asirio-babilonio, remontándose a un tiempo ancestral donde resulta verdaderamente complicado rastrear los inicios del mito.

Es probable que la tradición judaica heredase esta línea, que es la que llega hasta la actualidad, una versión trasmutada sitúa el origen de la figura de Lilith en la única referencia explícita que existe hacia ella en el Antiguo Testamento: «Los gatos salvajes se juntarán con hienas y un sátiro llamará al otro; también allí reposará Lilith y en él encontrará descanso» (Isaías 34: 14).

Estas suposiciones tienen su base en la interpretación que del Génesis bíblico $(1,27)$ se ha hecho. Antes de explicar que el Dios Yahvé dio a Adán una esposa llamada Eva a partir de su costilla, el texto dice: «Creó, pues, Dios al hombre a su imagen; a imagen de Dios lo creó; hombre y mujer los creó».

Según la definición de la Enciclopedia Británica, Lilith es:

Female demon of Jewish folklore; her name and personality are derived from the class of Mesopotamian demons called lilû (feminine: lilitu). In rabbinic literature Lilith is variously depicted as the mother of Adam's demonic offspring following his separation from Eve or as his first wife, who left him because of their incompatibility.

En el Zohar (obra principal de la Cábala), se hace referencia a Lilith como la perversa, la falsa, la ramera e, incluso, la negra ${ }^{1}$. Es importante conocer, a la hora de analizar la demonización de la figura de Lilita, que el Talmud hebreo narra su encuentro y posterior unión con el ángel Samael, que se rebeló contra dios, y a quien el cristianismo denomina Satán.

En Lilit y otros relatos, Primo Levi narra algunas de las más conocidas historias de Lilith en la tradición oral hebrea:

la historia de Eva está escrita y la sabe todo el mundo; mientras que la de Lilit sólo se cuenta oralmente, y por eso la sabe poca gente (bueno, no «la» sino «las», pues son muchas las historias) [...] El Señor no sólo los hizo iguales, sino que con la arcilla hizo además una forma única; mejor dicho, un Golem, una forma sin forma. Era una figura con dos espaldas; es decir, el hombre y la mujer ya juntos. Luego los separó de un tajo. [...] Adán quiso que Lilit se acostase en el suelo. Lilit no estaba de acuerdo. [...] Lilit vive precisamente en el mar Rojo, pero que todas las noches levanta el vuelo, se da una vuelta

${ }^{1}$ Esta interpretación no aparece dentro de la propia Biblia, sino en un Midrash (una interpretación, una exégesis no literal) que data del siglo XII, según Robert Graves y Raphael Patai en Los mitos hebreos. 
por el mundo, rompe los cristales de las casas en las que hay niños e intenta sofocarlos. Es menester estar atentos; si logra entrar, se la atrapa debajo de un plato volcado, y ya no puede hacer daño. Otras veces entra en el cuerpo del hombre, y éste queda embrujado. [...] Luego está la historia del semen. A ella le gusta mucho el semen del hombre, y anda siempre al acecho a ver dónde ha podido caer. Todo el semen que no acaba en el único lugar consentido, es decir, dentro de la matriz de la esposa, es suyo. [...] Por eso no hace más que parir. [...] Pero son también hijos de hombre, de cada hombre: hijos ilegítimos. [...] Pero me queda por contarte la historia más extraña, y no es extraño que sea extraña si se piensa que está escrita en los libros de los cabalistas, que son unos individuos sin ningún tipo de miedo. [...] los cabalistas decían que tampoco estaba bien que estuviera Dios solo, por lo que en el principio de los principios, se dio a sí mismo una compañera a la Shekiná, es decir, a su propia presencia en la creación. De este modo la Shekiná se convirtió en la esposa de Dios y, por tanto, en la madre de todos los pueblos. [...] Dios se quedó solo y, como sucede a la mayoría de nosotros, no pudo resistirse a la soledad y a la tentación y se buscó una amante. ¿Adivinas quién? Lilit, la diablesa. [...] Mientras Dios siga pecando con Lilit, habrá sobre la tierra sangre y dolor (Levi, 1989: 23-25).

La religión enfrenta a Lilith con Eva, que, pese a ser originariamente la culpable de la perdición de la humanidad, no deja de ser la «madre», y, por tanto, merecedora de respeto en alguna medida, mientras que la leyenda condenó a la insubordinada, rebelde y lasciva Lilith al castigo eterno de perder cada día un centenar de sus hijos. Ésta es la base de la leyenda que conduce a la tradicional asociación de la imagen de Lilith con el peligro sobrenatural que acosa a las parturientas y a los recién nacidos.

Siglos más tarde, la imaginería medieval tendió a fundir a Eva, tentada por el reptil, y Lilith, la mujer rebelde. Así, en diversas imágenes, como las miniaturas de los Hermanos Limbourg, que representan El Paraíso Terrenal en el manuscrito iluminado del siglo Xv, Les très riches heures du Duc de Berry, una forma zoomórfica, mitad mujer, mitad serpiente, se enrosca en el árbol y ofrece a Eva la manzana. Similar conjunción ofrece la obra de Kenyon Cox, donde, en la parte superior, Lilith aparece como una joven seducida (y quizá seduciendo) a la serpiente, con un largo y rizado pelo (tema característico y recurrente en estas interpretaciones), mientras que en la parte inferior, de nuevo mitad animal, mitad mujer, ofrece a Eva la manzana de la perdición. Esta simbiosis entre las diferentes características del mito de la mujer como pervertidora de la humanidad se dará también más tarde en obras como «Eve Pandora», de Gustave Adolphe Mossa (1907), donde la figura femenina aparece sosteniendo a un tiempo la manzana del pecado y la 
mítica caja abierta, mientras la serpiente bíblica se enrosca en torno a su hombre derecho.

En resumen, la demoníaca Lilith aparece, de un modo u otro, en la tradición asirio-babilónica, grecorromana, judaica y medieval (cuando abandonaría un tanto el imaginario religioso, para instalarse en la superstición con la encarnación en las figuras de las Lamias) ${ }^{2}$. Y con el compendio de características que la dan todos y cada unos de estos mitemas llega, casi intacta, hasta nuestros días, caminando por el fino sendero que separa lo bíblico de lo mitológico, lo transgresor (como han apuntado los más recientes estudios feministas) y lo perverso (según la lectura que tradicionalmente se ha hecho de su rebeldía hacia Dios y Adán). Leyenda o fe, lo cierto es que la imagen y las revisiones posteriores, que de esta mujer-demonio se han hecho, han dado lugar a uno de los temas de estudio de mitocrítica más recurrentes y polifacéticos en la historia de la literatura y la pintura hasta el día de hoy. Lilith convertida en el icono de la mujer situada fuera del círculo de lo correcto, la femme fatal, la prostituta, la pervertidora perversa.

\subsection{De lo mítico a lo literario}

Las primeras referencias a mujeres lascivas que se alimentan de sangre humana aparecen primero en la tradición clásica griega. Emparentadas con las arpías, mujeres con cuerpo de ave y garras afiladas que raptan a recién nacidos, de las que nos hablan entre otros Homero, Petronio y Apuleyo, hallamos a las estriges. Tanto Ovidio (Fastos) como Petronio (El satiricón) nos las describen como fruto de la unión entre hombres y arpías, mujeres aladas con garras de rapaces que se alimentan de la carne y la sangre de los recién nacidos.

Entre estos seres sangrientos destaca Empusa, un demonio femenino asociado a la diosa Hécate ${ }^{3}$, que se alimentaba de la sangre de los hombres

${ }^{2}$ En la mitología griega, Lamia era una reina de Libia a la que Zeus amó, hija de Poseidón o Belo y de Libia. Los celos de Hera la transformaron en un monstruo y la obligaron a matar a sus hijos (o, en otras versiones, mató a sus hijos y fue la pena lo que la transformó en monstruo). Lamia fue condenada a no poder cerrar sus ojos de tal forma que siempre estuviera obsesionada con la imagen de sus hijos muertos. Zeus le otorgó el don de poder extraerse los ojos para así descansar, y volver a ponérselos luego. Lamia sentía envidia de las otras madres y devoraba a sus hijos. Tenía el cuerpo de una serpiente y los pechos y la cabeza de una mujer. Pese a que es una figura esencialmente femenina, ocasionalmente se la ha considerado masculina o hermafrodita.

${ }^{3}$ Hécate fue originalmente la diosa de las tierras salvajes y los partos. En la Alejandría ptolemaica terminaría adquiriendo connotaciones de diosa de la hechicería y desarrollaría el papel de «Reina de los Fantasmas». 
tras haberlos seducido bajo la apariencia de una hermosa doncella. Algunas fuentes apuntan a la asimilación de la leyenda de Empusa por el pueblo judío, donde se la consideraba hija de la Lilith hebraica con la que comparte un gran número de similitudes.

La mayor parte de los rasgos que presentan las arpías, estriges y empusas son heredadas del mito hebraico de Lilith, que la concibe como un ser nocturno, lascivo y devorador de niños, enloquecida ante la maldición divina que la condena a ver morir cientos de sus hijos cada día. La mayoría de los historiadores y antropólogos coinciden en señalar que tanto los seres anteriormente mencionados como los vampiros, que caracterizan gran parte de la demonología de la Edad Media, tienen su origen en este mismo mito.

Esta imaginería de la mujer pérfida y cruel ha flotado durante siglos sobre la literatura y las artes, pero fue en el perfecto caldo de cultivo, creado por la concepción decimonónica del mundo, cuando la mujer fatal comenzó a tomar forma y a definirse por sí misma. Según Cirlot, Lilith es:

La primera mujer de Adán, según la leyenda hebrea. Espectro nocturno, enemigo de los partos y de los recién nacidos. [...] Su figura puede coincidir con Brunilda, en la saga de los nibelungos, en contraposición con Crimilda (Eva). Símbolo de la «madre terrible». [...] Lilith personifica la imago materna en cuanto reaparición vengadora, que actúa contra el hijo y contra su esposa (tema transferido en otros aspectos a la «madrastra» y a la madre política). No se debe identificar literalmente con la madre, sino con la idea de ésta venerada (amada y temida) durante la infancia. Lilith puede surgir como amante desdeñada o anterior "olvidada», cual en el aludido caso de Brunilda o como tentadora que, en nombre de la imago materna, pretende y procura destruir al hijo y a su esposa. Posee cierto aspecto viriloide, como Hécate «cazadora maldita» (Cirlot, 1970: 278).

Es de esta definición de la que partiremos para analizar los rasgos comunes del mito a través de la literatura y la pintura decimonónica. Es, sin embargo, imprescindible hacer algunas referencias a los orígenes literarios de este tipo femenino que invade las artes del XIX.

Como ya apunta Cirlot, la imagen de la mujer, desobediente, enfrentada directamente al concepto de maternidad (la mujer que por propia decisión no tiene hijos, o que incluso se revuelve contra ellos y los mata, como le sucede a Medea), se contrapone a la mujer-Virgen, la monja encerrada en su propio hogar, guardiana de su propia virtud y de la de su marido, el arquetipo femenino de la sociedad victoriana, que aspira a convertir a la madre en santa. 
La imagen arquetípica de la mujer como encarnación de «todas las categorías de lo execrable» (Sierra, 1975: 79) está definida por la figura literaria de Medea, definitiva para la construcción de la mujer fatal. Ella engloba lo femenino, lo bárbaro y lo animal en contraposición a los valores básicos de la sociedad patriarcal helénica. Es la madre que, como venganza por el despecho y el ultraje del marido, mata a sus propios hijos, al igual que la terrorífica Lilith. La perversión de la madre asesina atrajo por su condición de instinto antinatural a los románticos desde el principio.

Muestra de ello es la balada Lamia que en 1819 compuso John Keats y que supuso la raíz del parentesco entre los románticos y el mito de la mujervampiro:

\section{What wreath for Lamia? What for Lycius? \\ What for de sage, old Apollonius? \\ Upon her aching forehead be there hung. \\ The leaves of willow and of adder's tonge.}

El poema narra la historia de la joven Lamia, amante de Zeus. Se ve claramente aquí la asociación mítica entre la infelicidad de la madre y la práctica de una venganza cruel, que tiene en sus raíces la ruptura del orden natural establecido como problema de índole ontológica.

Mario Praz afirma que «siempre ha habido mujeres fatales en el mito y en la literatura, porque mito y literatura no hacen más que reflejar fantásticamente aspectos de la vida real, y la vida real ha ofrecido siempre ejemplos más o menos perfectos de femineidad prepotente y cruel» (Praz, 1999: 347), y es por esto por lo que el cambio de roles en la vida real acarrea siempre un cambio, habitualmente más marcado en la literatura.

Aunque la definición de este tipo de mujer y el camino hacia la construcción del estereotipo es propia de la segunda mitad del siglo XIX (la primera mitad está dominada más por el hombre fatal, el dandy de constitución byroniana, el tipo de seductor que habita en relatos como El vampiro, de Polidori, que tenía como víctima propicia a una mujer débil y enfermiza, la joven tísica oprimida por el corsé), el intercambio de papeles se rastrea ya en algunas composiciones anteriores al «giro» oficial del imaginario, como en la obra teatral de Goethe, Götz de Berlinchingen (1773), en la que el personaje de la condesa Adelaida adelanta este tipo de mujer que, impulsada por una gran ambición, utilizará para sus fines a los hombres que se encuentran a su alrededor. 
Otra de las semillas básicas, que dará lugar a la definitiva construcción de este mito, es la obra más conocida del inglés Mathew Gregory Lewis, El monje, demarcada como una de las primeras narraciones góticas, insertas en un romanticismo negro e hiperbólico. En ella, Matilde, mujer letal y seductora, es un instrumento del demonio que incita al pecado al virtuoso fraile Ambrosio, que, como castigo, termina muriendo de modo cruel y violento.

La mujer, como símbolo, aparece definida por Cirlot como:

El principio pasivo de la naturaleza. Aparece esencialmente en tres aspectos: como sirena, lamia o ser monstruoso que encanta, divierte y aleja de la evolución; como madre, o Mater Magna (patria, ciudad, naturaleza), relacionándose también con el aspecto informe de las aguas y del inconsciente; $y$ como doncella desconocida, amada o ánima (Cirlot, 1970: 312).

Es el primero de los papeles el que más atrajo a los románticos de la segunda mitad del siglo, serpiente incitadora. Es por eso que la literatura se puebla en esta época de Medusas, Cleopatras y Salomés, que no hacen sino reconstruir y reiterar el mito de la femme fatale, la mujer fuerte y dominante que, con su embriagadora belleza, conduce a los hombres, víctimas débiles ante sus perversiones, hacia el desastre y el infierno.

\section{LA MUJER PECADORA}

\subsection{La femme fatale, construcción del arquetipo en la pintura}

Aunque la mujer ha estado siempre presente en las artes plásticas, habitualmente ha figurado como objeto receptor del culto masculino, como pasiva representación de una sexualidad que ha tenido en el deseo del hombre su centro, principio y final. La proliferación de Venus desnudas en el Renacimiento europeo es clara muestra de esto. Desde La Venus dormida de Giorgione hasta la leve e intuida desinhibición de la Maja de Goya, todas estas mujeres desnudas no representan sino el deseo del varón. Los atributos propios de la mujer fatal, la iniciativa y la malevolencia, se desconocen, salvando puntuales excepciones que no pueden considerarse punto de partida por su pobre repercusión.

La simbiosis entre los mitos está en su apogeo durante el Renacimiento, cuando el resurgimiento del clasicismo grecorromano se une a la concepción de la tradición medieval para componer un nuevo conjunto de ideas que 
conforman el imaginario literario del momento que nos ocupa. En su representación de la pérdida del Paraíso, Miguel Ángel ilustra la Capilla Sixtina vaticana con la figura antropomórfica de una Lilith mitad serpiente mitad mujer que se inclina hacia Eva, interesada y displicente. Sin embargo, pese a la representación del mito en una de sus vertientes más habituales, las mujeres de Miguel Ángel carecen de ese hálito único que caracteriza a la mujer terrible por antonomasia.

Tendremos que esperar hasta poco antes del Romanticismo, cuando, coincidiendo con la aparición de la figura de la Adelaida de Goethe en Götz de Berlinchingen, el pintor de origen suizo Johann Heinrich Füssli, más conocido como Henry Fuseli, crea una serie de figuras que anticipan el modelo de la mujer fatal y que, pese a no encontrar repercusión en el arte posterior, anticipa la que será la imagen de la perversidad femenina.

Quizá el más claro de estos ejemplos sea la representación de la escena de El sueño de una noche de verano, titulada Titania acariciando a Bottom, donde, en medio de un ambiente de sensualidad y abandono, en la parte inferior, una joven de mirada malévola (la única figura que observa directamente al espectador) lleva a un viejo atado con una cadena, como si se tratase de un animalillo doméstico. Es habitual en las obras de Fuseli encontrar a la mujer como figura pérfida y poderosa y a los hombres siendo víctimas inocentes de sus engaños, como representan otros dos de sus conocidos óleos, The Ladies of Hastings y Fallstaff im Wäschekorb. La escasa repercusión que tuvieron estas obras y su distribución más bien minoritaria nos impiden hablar del comienzo del icono propiamente dicho.

Como en el ámbito literario, estas imágenes constituyen el esbozo de un cambio, adscrito más bien a la percepción del tópico de la mujer como objeto del arte que a la creación de un nuevo mito con todas sus consecuencias. Al igual que en la escritura, será necesario adentrarse en la segunda mitad del siglo XIX, imbuirse de lleno en los movimientos del prerrafaelismo y el simbolismo, para poder hablar de la creación intencionada de un arquetipo mítico a partir de la recuperación de la imagen del mito religioso hebraico, tamizada por la tradición y las supersticiones medievales, la circunstancia social que rodea a una mujer que comienza la andadura de la emancipación del patriarcado social y la concepción literaria del momento que estos cambios conllevan. 


\subsection{El cabello rojo y el prerrafaelismo}

La asociación de pintores, poetas y críticos ingleses, fundada en 1848, en Londres, por John Everett Millais, Dante Gabriel Rossetti y William Holman Hunt (más popularmente conocida como la Hermandad Prerrafaelita), fue la responsable de elevar la imagen de la mujer, como entidad seductora y perversa, a una categoría hasta el momento desconocida para la historia de la pintura.

Una de las principales características definitorias del prerrafaelismo, y un punto básico para la comprensión de su importancia en relación con este trabajo, es el desarrollo de los lazos entre la poesía romántica y el arte, una relación que, sobre todo Rossetti, también poeta, estuvo siempre interesado en desarrollar.

Durante los comienzos del movimiento, el prerrafaelismo tendió hacia los temas morales, para los que se inspiraba, sobre todo, en leyendas medievales y recreaciones religiosas. Con el paso del tiempo, las pinturas derivaron cada vez con más frecuencia hacia los motivos literarios, y es en este campo cuando, en más de una ocasión, se refleja en el arte una cierta tensión erótica que conforma el centro de la segunda etapa del grupo, y que será, para todos los críticos, la de mayor influencia de cara al simbolismo europeo posterior. Este erotismo subyacente y, en más de una ocasión, claramente inquietante, sacará a luz la figura de un tipo de mujer tan sensual como extraña, que ya prefigura las principales características femme fatale de fin de siglo. Los motivos más recurrentes serán la mirada ausente, la actitud laxa, levemente provocativa, y en cuanto a lo físico, el cabello abundante, suelto, en ocasiones rizado u ondulado, habitualmente rojo, y los ojos verdes, fríos, penetrantes.

Simbólicamente, el pelo, sobre todo femenino, es una manifestación energética. Para Cirlot (1970: 111), «la cabellera opulenta es una representación de la fuerza vital y de la alegría de vivir, ligadas a la voluntad de triunfo», características todas representativas de la imagen de esta mujer voluptuosa y dominante. Si el cabello es fuerza, en la mayor parte de los casos se relaciona también con el fuego, sobre todo si su color es el rojo, ya que los cabellos cobrizos han contado siempre con un significado venusino y demoníaco. No debemos olvidar tampoco que, para autores como Flaubert, el pelo es el «manto magnífico de la mujer en los tiempos primitivos».

Esta derivación se acentuará, sobre todo, en la obra de Dante Gabriel Rossetti. El artista englobará en las mujeres de sus cuadros la gran mayoría 
de los tópicos artísticos del mito, que se encumbrarán en una de sus obras más destacadas, Lady Lilith (1864-68), representativa por antonomasia de todo lo que aquí estamos comentando, y que forma parte de la serie de obras en las que el pintor traza el sendero de esta mujer fatal que todavía no ha alcanzado su plena madurez. Bajo la clara influencia de los personajes femeninos de Poems and Ballads (1866), de Swinburne, quien dedicó a Rossetti gran parte de su creación literaria, la figura representa una amalgama entre la Lilith creada en el Fausto, de Goethe y la de la Belle dame sans merci, de Keats. En relación a este cuadro, el pintor escribió en 1870 a su amigo el doctor Hake:

You ask me about Lilith - I suppose referring to the picture-sonnet. The picture is called Lady Lilith by right (Only I thought this would present a difficulty in print without paint to explain it), and represente a Modern Lilith combing out her abundant golden hair an gazing o on herself in the glass with that complete self-absorption by whose fascination such natures draw others within their draw circle. The idea which you indicate (viz: of the perilous principle in the world being female from de list) is about the most essencial meaning of the sonnet (Bornay, 2004: 132).

Históricamente, esta moderna Lilith, de la que nos habla Rossetti, coincide en el tiempo con los primeros intentos de la mujer para emanciparse en la sociedad decimonónica.

Será más tarde el movimiento simbolista el encargado de evocar, a través de la abstracción de los sentimientos, la forma concreta de la mujer que, si bien en algunas ocasiones toma el cuerpo de la madre, suele representarse más a menudo como la imagen pérfida de esa realidad dual en la que se divide el universo femenino:

Es la encarnación de la dominación del espíritu por el cuerpo [...]. Y aunque puede ser una musa inspiradora de la obra de arte, mucho más a menudo es su amenaza. Todo ello iba a despertar en el artista simbolista una morbosa seducción por el sexo, que irá pareja con un obsesivo temor por sus atractivos (Bornay, 2004: 98). 


\title{
3. LA LITERATURA DEL SIGLO XIX Y LA ATRACCIÓN POR EL OSCURO FEMENINO
}

\section{1. «La Belle Dame sans Merci». La mujer de los escritores decimonónicos}

En el poema «Hymne a la Beauté» canta Baudelaire:

\author{
Viens-tu du ciel profond ou sors-tu de l'abîme, \\ O Beauté? Ton regard, infernal et divin, \\ verse confusément le bienfait et le crime, \\ et l'on peut pour cela te comparer au vin (1998: 141).
}

Aunque la asociación entre crueldad y placer, entre dolor y pasión, no es en absoluto nueva para el mundo de la literatura (qué mejor ejemplo para esto que las obras del Divino Marqués), el hombre romántico se regodeó en descubrir y describir lo que ha dado en llamarse la «belleza medusea» por investigadores como Mario Praz (1999). Lo bello de lo horrible, o lo horrorosamente hermoso.

El comienzo de esta estética de lo horrendo tiene lugar en el poema que el cuadro La Medusa (de origen desconocido, pero atribuido originariamente a Leonardo da Vinci) inspiró a Shelley en 1819: «Its horror and its beauty are divine» (Shelley, 1969). El cambio de visión se hace palpable, lo que debería repeler atrae, en un nuevo apogeo de la estética de lo terrible, por lo que el «descubrimiento del horror, como fuente de deleite y de belleza, terminó por actuar sobre el mismo concepto de belleza: lo horrendo, en lugar de una categoría de lo bello, acabó por transformarse en uno de los elementos propios de la belleza» (Praz, 1999: 69).

Esta belleza voluptuosa es la raíz creadora de uno de los iconos de la literatura romántica por excelencia: el vampiro, cuyos detalles como figura mítica trataremos más adelante, y que en estos momentos ilustra a la perfección la imagen del vértigo de aquello que debería repeler, pero que atrae irremisiblemente.

Con lo cruel y lo macabro elevado a los altares supremos de la belleza, el campo artístico se encuentra perfectamente abonado para la aparición de la mujer fatal. La preeminencia de esta mujer diabólica en la literatura romántica hace del tipo de fémina angélica una sombra fugaz y vana que pierde toda la importancia que había tenido en la literatura anterior para convertirse ahora en 
un mero contrapunto de la mujer perversa. Esta belleza turbia desplaza el ideal femenino que hasta el momento encarnaba la esposa casta, la virgen, hacia la mujer infame, la prostituta, la adúltera. Se da la espalda a la blancura de María para acercarse hacia la turbulenta pasión indomable de Lilith.

Para poder realizar un acercamiento coherente a este arquetipo, analizaremos alguna de las representaciones de la perversión del Eterno Femenino a través de las caracterizaciones de estas mujeres en las obras de los literatos.

Tras la Adelaida de Goethe y la Matilde de Lewis, le llega el turno a Velléda, la maga patriótica de la obra de Chateaubriand, Les Martyrs, cuyo devenir literario tiene un marcado paralelismo con el de la obra de Lewis, con la diferencia de que aquí la protagonista no triunfa, sino que se mata al final. La mujer de Chateubriand inspirará el modelo para Salammbô de Flaubert, una mujer frígida, insensible y fatal cuyo sólo aliento pudre lo que le rodea.

Aunque si hay que marcar un momento clave para la construcción del arquetipo decimonónico, éste es, sin lugar a dudas, el instante álgido de la Carmen de Mérimée, cuando don José espeta a la mujer «eres un diablo», a lo que ella responde con el categórico «sí» y el beso que cierra la escena. La violencia y la pasión se encarnan en este modelo femenino, mortal para los hombres que la rodean, y a los que acaba llevando, como a José, a «transformarse en un ladrón y un asesino», pese a su voluntad. Será desde este momento, también, cuando el mito se relacione con el exotismo y la abierta sexualidad del modelo español.

El clima, lo caluroso, parece marcar en este punto la aparición del personaje en sucesivas novelas. Desde España hasta el trópico en Les Mystères de Paris de Sue, donde la diabólica criolla Cécily representa la sensualidad ardiente del Caribe, la joven de color, seductora y vampírica, cuya mirada atrae a sus víctimas lentamente, caracterizada por una «coquetería feroz», símbolos todos que terminarán formando parte del patrimonio iconográfico de la mujer fatal. En un momento de la obra el narrador nos remite a otras figuras femeninas igualmente seductoras y terribles al afirmar que Cécily mostraba «una corrupción digna de las reinas cortesanas de la antigua Roma».

Este exotismo, representativo de la necesidad de proyección fuera del mundo real, es común a la literatura mística del momento, y ambas, aunque de un modo mucho más visible la primera, contienen una base profundamente sensual que construirá el armazón sobre el que se levantan la inmensa mayoría de estas obras. 
La poesía de John Keats es el germen de lo que más tarde desarrollará la pintura de los prerrafaelitas. La balada La belle dame sans merci (1819), con su misterio mágico y doloroso, contiene el embrión de uno de los temas más habituales y recurrentes del mundo simbolista, la leyenda de Tannhäuser y su intento de redención tras disfrutar del placer y la sensualidad junto a la diosa Venus. Keats describe así a la mujer que embruja al caballero:

I met a lady in the meads,

Full beautiful-a faery's child,

Her hair was long, her foot was light,

And her eyes were wild.

I made a garland for her head,

And bracelets too, and fragrant zone;

She look'd at me as she did love,

And made sweet moan.

El negro abismo al que se ve abocado todo hombre que cae en los brazos de la hermosa y terrible mujer queda marcado en la advertencia onírica en los versos clave del poema:

I saw pale kings and princes too,

Pale warriors, death-pale were they all;

They cried — « La Belle Dame sans Merci

Hath thee in thrall!

Al despertar del sueño, al que la mujer le ha inducido, el caballero sólo ve «sus hambrientos labios en las sombras», que le abocan al destino, al vagar solitario y oscuro de aquéllos que han cedido a la tentación.

Tras Keats, uno de los poetas que más ha trabajado este tema es Algernon Charles Swinburne (1929: 88-89), que, quizá por haber escrito la poesía más controvertida en su época (eran recurrentes en sus obras los temas de sadomasoquismo, suicidio, lesbianismo y sentimientos irreligiosos), no ha disfrutado de la misma publicidad que algunos de sus contemporáneos de similar, o incluso inferior, calidad poética:

She holds my heart in her sweet open hands

Hanging asleep; hard by her head there stands,

Crowned with gilt thorns and clothed with flesh like fire,

Love, wan as foam blown up the salt burnt sands.

En estos versos del poema Laus Veneris (1866) el poeta recrea variaciones recurrentes del motivo del Eterno Femenino que encadena a su carro a 
héroes de todos los lugares y tiempos. Una Venus que en la Antigüedad representaba todo lo hermoso y sensual y que, en la imaginería cristiana, queda reducida a la siniestra figura del vampiro, de la perversa Lilith, devoradora de la esencia masculina, característica común a todas estas figuras, desde La Belle dame sans merci de Keats hasta las diversas Salomés de la literatura de fin de siglo.

A Swinburne y a su larga serie de filias eróticas, debe la literatura no sólo la determinación de ese arquetipo de mujer cruel y sádica que disfruta con el dolor de un hombre mas débil, sino también la creación del enamorado pálido e inferior a la enamorada, tan recurrente en la literatura de ese momento.

La sumisión ante la mujer, como fuente de erotismo y lujuria, es el leit motiv de su creación, y por tanto la definición de un ídolo femenino que influyó claramente en la pintura prerrafaelita y la literatura posterior. Los dramas del escritor están repletos de mujeres terroríficas y lujuriosas que llegan a afirmar, como en el caso de Rosamond (1860): «soy la mujer de todos los relatos, el rostro que siempre se encuentra en el rostro de la historia», aunque es en el personaje de María Estuardo, en Chastelard (1865), donde el poeta intenta realizar un verdadero acercamiento a este tipo de psicología femenina, más allá de sus íntimas fantasías. Una mujer a la que su amante describe de este modo (Swinburne, 1929: 320):
I know her ways of loving, all of them:
A sweet soft way the first is; afterward
It burns and bites like fire; the end of that,
Charred dust, and eyelids bitten through with smoke.

Este tipo de mujer será a la que, en Francia, remite Gautier, que tamizó sus creaciones del más fino y sensual exotismo en obras como Une nuit de Cléopâtre (1845), donde, contra el ambiente exótico, descrito con todo lujo de detalles, se recorta la figura de esta mujer, representación de la peligrosidad de la mantis religiosa. La llama que atrae y quema a quienes se aventuran a tocarla. No sólo la figura de la reina egipcia es clave en la obra de Gautier, la hermosa Nyssia del Roi Candaule representa la mujer fatal de Oriente, cuyos terribles efectos son instantáneos para los hombres con su sola visión:

Toujours est-il que Gygès resta immobile à l'aspect de cette Méduse de beauté [...] et d'ailleurs il avait été plutôt ébloui, fasciné, foudroyé en quelque sorte, que charmé par cette apparition surhumaine, par ce mostre de beauté. 
En estas palabras reúne Gautier los principios del mito, una mujer hermosa, fascinante, de una belleza sobrehumana, y tan perfecta que resulta inquietante, que más que encantar, fulmina. Es ésta la belleza de la que harán gala, entre otras, la Vénus d'Ille de Mérimée (1837), o la Pamphila de D'Annunzio (1893), reencarnación de Helena y Safo, que reúne en su sola persona toda la experiencia sensual del mundo, y que en su Poema Paradisíaco exclama (Praz, 1999: 390);

\author{
Por todos poseída, por el mendigo \\ y por el señor, cubierta de caricias \\ inmemorables, última prole tuya, \\ Elena, aún del misterio antiguo \\ circundada.
}

El tipo de mujer que confiesa en Noviembre (Flaubert, 1986: 11), a través de la boca de la sensual cortesana Marie, «serpiente y demonio»:

Ni los pobres ni los ricos, ni los bellos ni los feos, pudieron saciar el amor que les pedía que colmaran; todos débiles, languidecientes, concebidos en el tedio, engendros hechos por paralíticos que el vino embriaga, que la mujer mata.

Una hembra, y he aquí el punto clave de la construcción de esta femme, realmente fatal para quienes se cruzan en su camino, que siente la verdadera plenitud de la experiencia sensual sin ninguno de los tabúes y represiones que perseguían a sus predecesoras.

\title{
3.2. La narrativa gótica y la mujer vampiro
}

En un trabajo que analiza la figura de la mujer fatal, el mito de Lilith en el arte y la literatura romántica, no puede faltar un análisis, todo lo minucioso posible, de la creación y desarrollo de la figura de la vampiresa y, con ella, de la creación de todo un género a lo largo de esta época: la novela gótica.

Teniendo en cuenta todas las características de los personajes femeninos que hemos analizado hasta ahora, era del todo inevitable llegar hasta la conjunción de los dos elementos que atraen y repelen por igual al artista romántico: la belleza de la mujer y la muerte. Nace así la estirpe, descendiente directa del mito de Lilith, de la bella difunta, la mujer muerta que conserva, junto con una inevitable palidez (característica, por lo demás, 
inherente a todas ellas, vivas o no), su poder de atracción intacto, incrementado incluso por la sensación de peligro y de oscuridad que rodea su estilizada figura. Esta concepción entronca de manera directa con uno de los primeros puntos analizados, el horror de la belleza, la hermosura que debería repeler, pero que atrae con su contaminación y perversa voluptuosidad. Porque si algo tienen en común todas estas mujeres, desde la Carmilla de LeFanu (1972) hasta Luella Miller, de Mary Wilkins Freeman (1902), cuando el vampiro pasa de chupar sangre a devorar la vitalidad psíquica de sus víctimas, es la innegable atracción que han ejercido, primero sobre los demás personajes que las rodean, $\mathrm{y}$, evidentemente, sobre sus fascinados lectores.

Los orígenes de esta asociación entre el vampiro y la mujer se remontan a las primeras leyendas clásicas, desde Lilith, que según algunas historias se alimentaba del semen como esencia vital masculina, hasta las Lamias medievales. Sin embargo, el inicio para la literatura finisecular de la vampiresa lo marca la balada de Goethe, Braut von Korinth (1797), en la que la mujervampiro toma por primera vez la fuerza del personaje masculino de tipo byroniano y acarrea la desgracia a quien osa acercase a ella.

En 1819, en la tragedia The Cenci, Shelley escribiría (acto IV, escena I), avanzando la esencia de la mujer-vampiro como condenada, privada de la gracia de Dios, como más tarde lo estará la Belle dame de su balada (Praz, 1999: 380):

and when dead,

As she shall die unshrived and unforgiven,

A rebel to her father and her God,

Her corpse shall be abandoned to the hounds;

Her name shall be the terror of the earth;

Her spirit shall approach the throne of God

Plague-spotted with my curses. I will make

Body and soul a monstrous lump of ruin.

Porque en esencia, esta mujer no tiene por qué ser un vampiro «de manual» para encarnar todo lo que esta figura representa, ya que el tipo vampírico también se perfiló en estas mujeres sádicas, que disfrutaban con el horror de sus enamorados, como la impactante Clara, del Jardin des supplices, de Mirebau, donde el espectáculo del horror de la cárcel china conduce a la joven inglesa al éxtasis sexual, en una escena que recuerda a los más retorcidos momentos de la poesía de Swinburne. Pero, sin lugar a dudas, es La muerta 
enamorada de Gautier, la bella cortesana Clarimonda, quien da preeminencia a un género ya inaugurado por Goethe y Lefanu.

En la figura de Clarimonda se unen la voluptuosidad y la muerte desde el comienzo, cuando el abad Serapione cuenta de ella que murió «después de una orgía que duró ocho días y ocho noches» (Gautier, 2001: 39):

Sobre Clarimonda se han contado historias muy extrañas [...] Se ha rumoreado que era una ghoul, una mujer vampiro; pero yo creo que era el propio Belcebú en persona.

La sensualidad se hace explícita cuando el sacerdote Romualdo se corta un dedo por casualidad (Gautier, 2001: 54):

Sus ojos recuperaron entonces el brillo, y noté en su cara una expresión de salvaje y feroz alegría que hasta entonces nunca había notado. Saltó del lecho con agilidad animal — con la agilidad de un mono o un gato- y se lanzó sobre mi herida, que succionó con indescriptible voluptuosidad [...] entrecerraba los ojos, cuyas verdes pupilas no eran ahora redondas, sino oblongas.

En todo caso, la lección final que la hermosa Clarimonda inspira en el joven cura está clara: «Nunca mires a una mujer [...], bastará un segundo de distracción para que te pierdas para toda la eternidad».

La atracción que sienten los escritores del XIX hacia la mujer-vampiro como representación de la mujer fatal, según Mario Praz, viene dada por el hecho de que «la figura de la Mujer Fatal encarnada sucesivamente en todos los tiempos y en todos los países, un arquetipo que reúne en sí todas las seducciones, todos los vicios y todas las voluptuosidades» (Praz, 1999: 392), es, sin lugar a dudas, la culminación de la atracción y de lo peligroso. Lo fatal y lo pútrido, en toda la amplia y posible extensión de la palabra, encarnada en la suprema crueldad sensual, que refleja el consentimiento del joven Romualdo, que, a sabiendas de la verdadera naturaleza de su amante, permite que ella, cada noche, le arranque la sangre, la vida, y la posible salvación de su alma, a cambio del irrepetible placer de los sentidos que Clarimonda le proporciona.

\section{CONCLUSIONES}

Las características inherentes del mito hebraico de Lilith conllevaron su propia perversión a través de los siglos. El momento histórico vivido a fina- 
les del siglo XIX, la creación del movimiento romántico y los nuevos roles que las mujeres comenzaban a jugar, hicieron de este instante el adecuado para revivir un personaje cuya imagen ha sido utilizada siempre a tenor de las necesidades de la élite patriarcal: como advertencia del peligro para las desobedientes jóvenes hebreas, como sentimiento de la antimujer, la antimadre, la esencia pecadora para el puritanismo europeo de los siglos XVIII y XIX y, actualmente, como bandera del feminismo que ha tomado de ella la rebeldía y la ruptura con el orden establecido. Y muchas otras vertientes cuyo análisis daría lugar a complejas y elaboradas relaciones, para las que apenas nos queda espacio en este estudio: la madrastra del cuento de hadas, la reina poderosa, cruel y fría - que va desde Hans Christian Andersen hasta la que aterroriza a la Alicia de Lewis Carroll, que más tarde aparecerá con el nombre de Lilith en Las crónicas de Narnia-, o Catherine, esencia de la vitalidad salvaje en Cumbres borrascosas, etc.

No es necesario estar más o menos de acuerdo con estas posturas para intuir que el miedo (o la atracción) por la mujer que no se atiene a las normas impuestas ha movido durante siglos a escritores y artistas a retratar a Lilith como el ejemplo perfecto de esta postura. El camino que va desde esta imagen inicial hasta la mujer fatal como postmoderno fetiche en la actualidad, ha estado repleto de vericuetos y senderos escabrosos que encontraron su comienzo en la imagen de los literatos románticos que, a partir de su concepción de la imagen de la mujer — desde la aparente sencillez de Shelley hasta la, también aparente, perversión de Swinburne-, construyeron con sus textos el arquetipo del mito, que dejó de serlo con su popularización para convertirse en una tipología recurrente y maniquea a comienzos del siglo $\mathrm{xx}$, con su inserción en la industria del cine y el best seller. Una imagen que, pese a haber perdido en la creación artística su impulso inicial, sigue grabada a fuego en el imaginario literario de los lectores de la poesía y narrativa decimonónicas.

\section{REFERENCIAS BIBLIOGRÁFICAS}

BAUDELAIRE, Ch. (1998). Las flores del mal. Madrid: Cátedra.

BORNAY, E. (2004). Las hijas de Lilith. Madrid: Ensayos Arte Cátedra.

CIRLOT, J. E. (1970). Diccionario de símbolos. Barcelona: Labor.

DIJSTRA, B. (1994). Ídolos de perversidad. La imagen de la mujer en la cultura de fin de siglo. Madrid: Club de Lectores. 
FLAUBERT, G. (1986). Noviembre: fragmentos de un estilo cualquiera. Barcelona: Muchnik.

GAUTIER, T. (1955). Le Roman de la Momie. Paris: Classiques Garnier.

KEATS, J. (1978). Poesía completa. Edición bilingüe. Tomo 2. Barcelona: Ediciones 29.

- (2007). Poemas escogidos. Madrid: Cátedra.

LEVI, P. (1989). Lilit y otros relatos, Barcelona: Ediciones 62.

PANOFSKY, D (1975). La caja de Pandora: aspectos variables de un símbolo mítico. Barcelona: Barral.

POE, E.A. (2000). Poesía completa. Madrid: Hiperión.

- (2000). Relatos. Madrid: Cátedra.

PRAZ, M. (1999). La carne, la muerte y el diablo en la literatura romántica. Barcelona: El Acantilado.

SHELLEY, P. B. (1969). Posthumous poems of Shelley: Mary Shelley's fair copy book. Montreal: McGill-Queen's University Press.

— (1997). No despertéis a la serpiente. Madrid: Hiperión.

- (1998). Prometeo liberado. Madrid: Hiperión.

SIERRA GONZÁLEZ, A. (2005). «Medea y el derecho materno». En Las hijas de Pandora: historia, tradición y simbología, I. Calero Secall y V. Alfaro Bech (eds.), 79-88. Málaga: Universidad de Málaga.

VV.AA. (2001). El Vampiro. Madrid. Siruela.

- (2001). Vampiras. Antología de relatos sobre mujeres vampiro. Madrid: Valdemar.

- Felices pesadillas. Los mejores relatos de terror. Madrid: Valdemar.

SWINBURNE, A. Ch. (1929). Select Poems of Algernon Charles. London: John Lane the Bodley Head LTD.

- (1926). The Complete Works of Algernon Charles Swinburne. Vol. VIII. Tragedies. London: William Heinemann LTD. 


\section{Dominios de Internet consultados}

http://www.britannica.com

http://www.geocities.com/englishromanticpoets

http://www.gutenberg.org

http://es.wikipedia.org

http://www.john-keats.com

http://swinburnearchive.indiana.edu

http://www.tate.org.uk 